\title{
On Considering the Application of Amartya Sen's Capability Approach to an Information-Based Rights Framework
}

\author{
Johannes Britz, Anthony Hoffmann, Shana Ponelis and Michael Zimmer* \\ University of Wisconsin
}

Peter Lor

University of Pretoria

*Corresponding author:

Michael Zimmer, School of Information Studies, University of Wisconsin - Milwaukee, NWQ-B, Room 2531, PO Box 413, Milwaukee, WI 53201 USA. Tel. p1 414-229-3627

Email: zimmerm@uwm.edu

\begin{abstract}
We live in an information society, and, resultantly, significant attention is devoted to ensure "information-based rights"' are protected among other essential human rights. Fostering and protecting information-based rights is essential to human well being, and the traditional strategies to support these rights focus on ensuring free and unfettered access to information, such as the right to education, the freedom to read, or providing for fair use of copyright-protected works. While ensuring informational goods and services are accessible is necessary for participation in our contemporary information society, we argue, however, that given the complexity of our information environment, additional factors must be considered within any information-based rights frame-work. Building on Amartya Sen's capability approach, we suggest that individuals' ability to access and use infor-mation is influenced by their relative capabilities. Those advocating for information-based rights -
\end{abstract}


such as the free software, access to knowledge, and open access movements - must adjust their focus to include not only achieving access, but also the fostering of human capabilities.

Keywords: capability approach, Amartya Sen, information rights, information access, information literacy

\section{Introduction}

Our starting point is that we live in an information society, and that, resultantly, significant attention is devoted to ensure "information-based rights" are protected among other essential human rights. Fostering and protecting information-based rights is essential to human well being, and the traditional strategies to support these rights focus on ensuring free and unfettered access to information, such as the right to education, the freedom to read, or providing for fair use of copyright-protected works. Clearly, access to information should be regarded as an instrumental and basic human right because, as Britz and Lor (2010: 17) note, "any vision of the successful implementation and protection of our civil, political, cultural, economic and social rights without the right of access to information pertaining to these rights, would be futile."

While ensuring access to informational goods and services is necessary for participation in our contemporary information society, Britz and Lor (2010: 18) also argue for increased focus on information literacy as the "enabler of the right of access to information and instrumental to human freedom." We agree with this position, and extend the concept of 
information literacy to reflect the complexity of our information environment. That is, beyond merely providing access additional factors related to literacy must be considered within any information-based rights framework. Building on Amartya Sen's capability approach, we suggest that individuals' ability to use information - to become information literate - is influenced by their relative capabilities, which are in turn influenced by three key factors:

- Personal characteristics, such as the intellectual capacity, level of education, skills and physical conditions

- Social characteristics, including hierarchies in society, social norms, public policies, and cultural practices

- Environmental characteristics, which include climate, infrastructure, and the availability of related public goods and services

Any robust information-based rights framework must recognize the complexities of the personal, social, and environmental factors that shape an individual's relative ability to actualize mere access to information into meaningful use and benefit, constituting the full enjoyment of information-based rights. Those advocating for information-based rights such as the free software, access to knowledge, and open access movements -must adjust their focus to include not only achieving access, but also the fostering of capabilities.

After introducing Sen's capability approach, this paper will discuss how the personal, social, and environmental factors shape individuals' capabilities to capitalize on their access to information and knowledge, and conclude by calling for the incorporation of 
Sen's capability approach into future information-based rights frameworks. As an initial probe, this paper sets the stage for a more applied treatment of how Sen's capability approach can be implemented into specific ethical and policy debates. Together, the two papers will work towards ensuring we move from simply codifying access to information toward actualizing its use and benefit in support of human well-being.

\section{Sen and human capabilities}

The capability approach has its philosophical roots in Karl Marx, Adam Smith and John Stuart Mill (Robeyns, 2003; Clark, 2006). The main pioneers of this approach are the economist and philosopher Amartya Sen, whose first publication on the capability approach appeared in 1979, and the philosopher Martha Nussbaum, a student of Sen, who started to publish on this topic in 1988. Sen (1995) initially saw his approach as providing an evaluation space for human well-being and not as a framework for the development of a theory of justice. Nussbaum took a more specifically social justice approach but both authors argued that the focus of development theories and social evaluations and policies should be on what people are able to do and what they can become, rather than on simply what resources or goods are available within a given society.

Much of the justification for the capabilities approach is developed by refuting positions central to social contractualist approaches to justice, and in particular John Rawls' justice as fairness. For Rawls, the primary subject of justice is the basic structure of society: by setting up and maintaining institutions according to his two principles of justice, we can achieve justice through the justness of our shared background (i.e., the basic structure of society, against which we all live our lives) (Rawls, 1971). Sen criticizes them all for what 
he views as an over-reliance on institutions or institutional arrangements for the realization of justice. What this over-reliance overlooks, he thinks, is the "inescapable relevance" of human behavior (Sen, 2009: 67). This does not mean, however, that Sen thinks we should abandon discussion of institutional arrangements altogether; rather, he holds that we should be equally concerned with institutions and behavior (and the ways that each influences the other).

Instead of focusing on institutional arrangements, Sen emphasizes the need for an effective and objective metric by which to measure levels of justice within and across societies. "Any substantive theory of ethics and political philosophy, particularly any theory of justice," Sen (2009: 231) insists, "has to choose an informational focus, that is, it has to decide which features of the world we should concentrate on in judging a society and in assessing justice and injustice." Before describing Sen's position, it is helpful to briefly outline the informational foci that he views as ultimately inadequate. First, Sen views capabilities as preferable to subjective, utilitarian-based measurements of happiness or total welfare, in the tradition of Bentham, Mill, and Sidgwick. He argues that developing just distributions based on utility is problematic, as it allows for unacceptable outcomes. For example, measurements based on maximizing marginal utility "can be deeply unfair to those who are persistently deprived, since our mental make-up and desires tend to adjust to circumstances, particularly to make life bearable in adverse situations" (Sen, 2009: 282). Or, to put it another way, it seems counter to justice to assume that we must treat the needs of a person who requires only a piece of bread to be happy as equal to those of a person that requires expensive caviar to achieve similar levels of happiness. Second, Sen argues against what might best be referred to as "Rawlsian resourcism," that is, measuring justice 
based on the availability of primary goods for members of a given society, as Rawls' theory of justice is designed to do. Focusing on a specific bundle of primary goods would be appropriate, he thinks, if all people possessed roughly a similar ability to use such goods. As Sen (1979: 215) puts it: "If people were basically very similar, then an index of primary goods might be quite a good way of judging advantage." The problem, however, is that people are not very similar. "[In fact], people seem to have very different needs varying with health, longevity, climatic conditions, location, work conditions, temperament, and even body size (affecting food and clothing requirements)" (Sen, 1979: 216). Measuring justice in terms of the availability of primary goods, then, does not properly account for relevant differences between individuals.

Instead of measuring for utility or resources, Sen (2009: 231-232) advocates a measurement based on capabilities, or, "the freedom that a person actually has to do this or be that - things that he or she may value doing or being." Consequently, a capabilities metric concentrates on individual capabilities, that is, in terms of what people are able to do and to be. This focus on human capacity brings a new emphasis on human development and the fulfillment of human needs not in terms of subjective well-being or resources, but on the capabilities of individuals to convert available goods into meaningful opportunities to fulfill valuable ends. In other words, it takes as its subject the ability of individuals to achieve substantive freedoms. It is through this measurement, then, that we can begin to address issues of justice not in some ideal sense, but in reality—by recognizing and addressing issues that prevent individuals from converting goods into opportunities or freedoms. Such obstacles may include (but are not limited to) poverty, unemployment, and 
lack of education. Moreover, capabilities, Sen believes, are conducive to relational comparisons within and across societies, allowing us to assess justice on a global scale.

Sen (1993) refers to conversion of goods into substantive freedoms as functions. Functions can, for example, include working, the ability to rest, to be healthy and to be educated. Functioning is therefore the use that a person has of commodities that are available and that such a person commands. Sen $(1993,1999)$ makes an important distinction between:

- achieved functions - actions and activities that have been realized and

- capabilities - what is effectively possible to do to achieve well-being. This is also referred to as human 'freedom'. A capability in other words reflects a person's ability to achieve a particular function in various ways. A strength of Sen's approach is that there is no one particular set or list of capabilities.

However, functions and capabilities are closely related. According to Sen (1987: 36) a

"function is an achievement, whereas a capability is the ability to achieve. Functionings are, in a sense, more directly related to living conditions, since they are different aspects of living conditions. Capabilities, in contrast, are notions of freedom, in the positive sense: What real opportunities you have regarding the life you may lead."

What matters in other words is not what you have, but what you can do with what you have. 
According to Sen, people must have the freedom (capabilities) to be what they want to be, to live their lives according to their choices. These capabilities, if available, allow effective choices for individuals in terms of what they want to be. In practical terms it means that people must have, for example, the opportunity to work and to be educated and be part of a community.

As an interdisciplinary approach, the capability approach deals with the full terrain of human development and in a nutshell can be defined as an approach dealing with social change in society by providing a normative framework for the analysis and evaluation of social arrangements, but more specifically for the well-being of individuals. In other words, social evaluation of poverty and inequality is not done in exclusively monetary terms or empirical measures of levels of access. As an approach it identifies those social and structural constrains that influence and restrict human development and well-being that are the root cause of the imbalances identified by such empirical measurements of inequality or information poverty (Sen, 1993; Robeyns, 2003; Kuklys, 2005).

\section{Capabilities and information-based rights}

The capability approach is important for the study of information-based rights and human well-being because the focus is not only on the articulation and codification of rights into legal systems but also on the ability and freedom of people to exercise these rights, thereby enhancing their human well-being and potential to seek self-fulfillment. It also allows one to differentiate between individuals in terms of choices to exercise their rights, based on their different sets of capabilities and how these impact on their ability to benefit from exercising basic information-based human rights. As an approach it also allows for the 
notion of human responsibility to be introduced. The ability and opportunity for an individual to make choices, and for different people to make different choices due to personal and environmental diversity, acknowledges a certain level of human responsibility regarding choices that are made. Acknowledging human diversity is central to Sen. According to Sen (1992: xi) human diversity “.... is no secondary complication (to be ignored, or to be introduced 'later on'); it is a fundamental aspect of our interest in equality".

To illustrate the relationship between information-based rights and the capability approach it is important to recognize that individual must posses more than just the freedom to achieve an information-based goal, but also have the means to achieve. Means to achieve refers to the availability of those products and services needed to achieve human wellbeing; these goods and services are not limited to commercial transactions. The main characteristic of a product or service is the fact that it enables a function. For example, we are interested in a library because it allows access to certain information we need to make certain choices.

As argued in the introduction, the availability and use of information products and services are influenced by three factors. Firstly, there are personal characteristics such as intellectual capacity, level of education, skills and physical condition that influence the way in which a person is able to convert the product into a function. If a person is illiterate, access to books or other text-based material in a library will be of limited help to enable the function of being informed. These personal characteristics will therefore impact the 
way in which a person can exercise and benefit from their information-based human rights such as access to information and their right to freedom of expression.

The second factor is social characteristics. These include hierarchies in society, social norms, public policies, rules and procedures, cultural practices including gender roles and discriminating practices (Robeyns, 2003: 12). Women in certain countries are, for example, forbidden to drive cars. Based on this social norm, embedded in public rules and regulations, women have limited means to enable the function of mobility. The functionality, and by implication the right of being informed and being knowledgeable is also severely limited in those cultures where girls, based on social norms, are excluded from certain levels of education. This approach therefore acknowledges the normative importance of groups in particular as it relates to the articulation of information-based rights.

Environmental characteristics, which include climate, infrastructure, and public goods, are the third factor that influences the way in which products and services can be converted into individual functioning and that can influence the way in which people exercise their information-based rights. There is no or little use for a library if people do not have the means (transport) to get to the library to actually use it. Another example is the establishment of telecentres in the Sahara desert. However, if the computers at these centres are not adequately protected from environmental characteristics such as the heat and the sand, their effectiveness will be limited. 
In many cases factors are interwoven. For example, all scholars have the right to freedom of thought, to conduct their research without impediment, and to communicate their ideas and findings in order to achieve their full potential. In Africa these information-based rights are captured in the Kampala Declaration on Intellectual Freedom and Social Responsibility in 1990, according to which every African intellectual shall enjoy freedom of movement within his/her country and across its borders (Article 4) and have the right to pursue intellectual activity without hindrance subject only to universally recognised principles of scientific enquiry and ethical and professional standards (Article 6). However, the Institute of International Education, administrator of the Scholar Rescue Fund, reports that Africa is "clearly [one of] the major regions from which scholars seeking rescue [from persecution, intimidation, repression] come" seeking safe spaces to pursue their work outside of their homelands (Jarecki and Kaisth, 2009: 27). Furthermore, African scholars still face challenges with respect to exercising their freedom of movement and freedom of speech. At a conference in Ghana in April 2009 it was reported that restrictions on travel or freedom of movement inhibit scholars' capabilities and means to achieve. In fact, one of the conference recommendations was that mechanisms need to be developed to monitor the implementation of the Kampala Declaration (Summary Report, 2009). In these instances African scholars are prevented from achieving their potential through both social and political factors that limit their relative capabilities.

As another example, Dralega (2009) investigated the use of information and communication technologies (ICTs), especially community radio, and how innovative use of ICTs can be combined with "endogenous, people-centered, and participatory processes" to promote development of a rural community in Uganda. She emphasized the active 
participation of the community, empowerment and incorporation of local culture. One radio program, Enkumbi Telimba, promoted information exchange among farmers. "Good farmers" were identified and helped by radio staff to develop radio scripts to give advice and share their knowledge. Another radio program, Senga, was concerned with sex education and family responsibilities. Although various family issues were dealt with (not only sex education but also cleanliness in the home, children's upbringing, puberty, the role of men and women in the home), the bulk of the programs were devoted to the sexual preparation of young women for marriage, "since all ladies are traditionally expected to grow up and get married and serve their husbands' sexual desires" (Dralega, 2009: 30).

Although the project demonstrated many laudable characteristics of modern communitycentered development theory, Dralega also pointed to a number of instances where the community radio service was not functioning as an emancipatory medium, and analyzed "the social disjunctures and social embeddedness of the technologies to unmask some of the hidden conflicts, 'oppressive' practices, and power structures" of the use of ICTs in development (Dralega, 2009: 35). One aspect is the clash between culture and modernity: cultural diversity can also be an obstacle to development goals and human rights. Specifically she refers here to the Senga program that she sees as promoting the subordination of women to men through cultural practices that instead should have been challenged. (Dralega, 2009: 36). Similarly, in a program devoted to herbalists, the herbalist participants disputed scientific research and promoted traditional practices that put the listeners at risk, and programs on safe motherhood, family planning and the prevention of AIDS conflicted with the beliefs and roles of traditional birth attendants. Thus she raises the question: "how can the $\mathrm{CMC}$ [community multimedia center] reconcile the promotion 
of local knowledge and practices with 'modernist' conceptions of safe childbirth, maternal health, women's emancipation, and a healthy community?" (Dralega, 2009: 36). She also addressed the political issues inherent in the use of ICTs such as gender roles and skewed participation (favoring wealthier, more powerful community members).

The availability and usability of products and services to enable human functioning is, as argued by Sen and revealed by Dralega above, tied to the complex arrangement of capabilities that are, in turn, individually and contextually determined. Therefore, a clear understanding of individual, social, structural and environmental conditions and circumstances is a prerequisite for understanding and knowing the abilities of people not only to put available products and services to use to enable certain functionalities but also to allow them to exercise and actualize their basic information rights.

However, the capability approach does not use the function (for example, visiting the library or driving a car) as the ultimate normative measurement to evaluate society. The focus is rather on the real freedom of individuals, that is, in the words of Robeyns (2003: 13), concerned "...with their capability to function, and not with [their] achieved functioned [sic] levels" (emphasis added). Functions are what we are and what we do in life whereas capabilities are the "...alternative combinations of functionings that this person can achieve and from which she can choose one vector of functionings" (Robeyns, 2003: 13, emphasis added). Sen (2002) refers to this as the idea of opportunity. The focus of this approach is therefore on the ability of people to make choices (freedom to achieve) of what they want to be (achievements), and this can differ from individual to individual and from context to context. Products and services are important, not in themselves, but in 
terms of their effectiveness in the development of the lives of people and in allowing them to perform their chosen function. This "freedom to achieve" can only be realized when individuals have access to relevant information and where they can benefit from the use thereof as it relates to the maximization of opportunities.

Whether the focus of social analysis should be on achieved functioning or the freedom to achieve these functions (capabilities) will also differ and will be determined by context. For example, the capability approach might focus on the limited achieved functioning of achieving access to information with a person who is proficient in using a Web search engine, but is subject to a censored Internet experience due to geographic location (in China, perhaps). The focus of the capability approach shifts, however, to the capabilities and freedom to achieve the function of accessing information for those who might have full access to an unfiltered Internet (in the United Kingdom, for example), but does not possess the skills - the ability - to successfully navigate the Web.

Not only does this approach allow one to evaluate society based on either capabilities or achieved functionalities, but it also recognizes individual differences. Two people, with the same capability sets, living in the same place, having equal access to products and services including information, might end up with different sets of achieved functioning because they made different choices based on a different set of priorities or because of personal or social-political constrains such as a lack of education or limited access to relevant information. This explains, according to Sen (2002), why the focus in social analysis should not be on achieved functioning only, but also on capabilities. 
The capability approach has therefore some very important implications for the understanding of information-based rights and related policy recommendations. This approach re-emphasizes the fact that access to essential information and the ability to benefit from this information is one of the fundamental sets of capabilities needed to achieve human well-being. One can even rephrase Sen (1993) by stating that the ability to benefit from information is a "basic capability" (in his work Sen identifies certain "basic capabilities"). Not only is information essential to human well-being, but it is instrumental to our freedom to make choices and to create opportunities to achieve this well being. The freedom to access information can thus be seen as a "fundamental freedom" that contributes to overall freedom. "Information freedom" can therefore be added to the list of five instrumental freedoms listed by Sen (1999: 38). These are: 1) political freedoms; 2) economic facilities; 3) social opportunities; 4) transparent guarantees and 5) protective security.

As an approach it also explains and facilitates different contexts of people as it relates to their ability to use and benefit from basic information rights. It allows focusing on different individuals within different settings by focusing on each individual's unique set of capabilities such as command of language, levels of literacy and the availability of services to access information in a particular context as well as the choices individuals make in different contexts.

The capability approach can furthermore be used to explain how individual informationrelated attributes such as intellectual capacity and visual impairment (in terms of access to information) as well as social amenities including the political economy of the distribution 
of information, intellectual property regimes and social settings (moral values and censorship) determine how products and services are converted into functions. Material assets alone are not enough to convert products and services into functions. Access to essential information and the ability to benefit from it is also crucial. Society's contribution to facilitate access to information and to ensure that people benefit from it through education is therefore not only an economic necessity but also a moral imperative.

The capability approach therefore provides a normative framework to evaluate society's structure and policies based on the core principle of human well-being. Applied to our ability to exercise and benefit from our basic information rights it asks, for example, whether people are information literate (achieved functions) and whether resources (for example, policies and taxes) are available to support the realization of capabilities, such as schools, libraries, information literacy program and access to the Internet. Are resources present, accessible and affordable to those who need them to achieve their well-being, leading them to self-fulfillment? In other words, are society and policies structured in such a manner that they accommodate and support actions and activities to enhance higher levels of information literacy allowing therefore people to exercise their basic right of accessing information? Thus the capability approach will evaluate whether, and if so, to what extent, conditions are met to allow this capability (to be information literate) that will allow individuals to choose, Sen's "human freedom", to actualize their goals. Resources required will include basic information rights such as the protection of freedom of expression, the right of access to information as well as a fair and just intellectual property regime that protects owners of intellectual property, but at the same time allows access to information and information resources. 


\section{Conclusion}

In the above sections we have argued that the availability and usability of products and services to enable human functioning is complex and can differ from individual to individual, and thus an information-rights framework focused merely on ensuring access to information will fall short no matter how thoughtfully it has been codified in laws and conventions. It becomes necessary to recognize how individual, social, structural and environmental conditions and circumstances impact an individual's ability to put available products and services to use to enable certain functionalities, and therefore be empowered to exercise and actualize their basic information rights.

Those advocating for information-based rights, then, must turn their focus from access to fostering capabilities. For example, the free software, access to knowledge, and open access movements have all made significant contributions to ensuring individuals across the globe have access to the information and information-based tools they need to thrive and reach their full potential. However, when considering these important advocacy efforts through the lens of Sen's capability approach, it becomes clear that merely providing access is not sufficient. Instead, we must work towards re-framing our information rights frameworks and agendas to ensure individuals are provided the opportunities - the capabilities - to actualize codified access into actual human well-being. This paper has set the groundwork for a more applied treatment of how Sen's capability approach can be implemented into these ethical and policy debates. Together, the two papers will work towards ensuring we move from simply codifying access to information toward actualizing its use and benefit in support of human well-being. 


\section{References}

1. Britz $\mathbf{J}$ and Lor P (2010) The right to be information literate: the core foundation of the knowledge society. Innovation 41: 8-24.

2. Clark DA (2006) The capability approach: its development, critiques and recent advances [online]. Global Poverty Research Group W-P-S-032. Available at: http://www.gprg.org (accessed 4 April 2011).

3. Dralega CA (2009) Participatory ethos, multimedia experiments, and disjunctures in community media in Uganda. Ecquid Novi: African Journalism Studies 30(1): 24-41.

4. Jarecki HG and Kaisth D (2009) Scholar Rescue in the Modern World. New York: Institute of International Education.

5. Kuklys W (2005) Amartya Sen's Capability Approach: Theoretical Insights and Empirical Applications (Studies in Choice and Welfare). New York: Springer.

6. Rawls J (1971) A Theory of Justice. Cambridge: Belknap Press.

7. Robeyns I (2003) The capability approach: an interdisciplinary introduction, revised version 9 December 2003 [online]. Available at: http://www.capabilityapproach.com/pubs/323CAtraining20031209.pdf (accessed 4 April 2011).

8. Sen A (1979) Equality of What? Tanner Lecture on Human Values. In: Tanner Lectures, Stanford University

9. Sen A (1987) The Standard of Living: Tanner Lectures on Human Values. In: Tanner Lectures, Cambridge University

10. Sen A (1992) Inequality Reexamined. Oxford: Oxford University Press. 
11. Sen A (1993) Capability and well-being. In: Nussbaum M and Sen A (eds) The Quality of Life. Oxford: Clarendon Press, pp.30-53.

12. Sen A (1995) Gender inequality and theories of justice. In: Nussbaum M and Glover J (eds) Women, culture and development: a study of human capabilities. Oxford, UK: Clarendon Press, pp.259-273.

13. Sen A (1999) Development as Freedom. Oxford: Oxford University Press.

14. Sen A (2002) Response to commentaries. Studies in Comparative International Development 37(2): 8-86.

15. Sen A (2009) The idea of justice. Cambridge, MA: Belknap Press.

16. Summary Report (2009) Academic Freedom In West African Universities, University Of Ghana, Legon, 15-16 April 2009 [online]. Available at: http://scholarsatrisk.nyu.edu/Documents/Ghana_report.pdf (accessed 23 February 2011).

17. The Kampala Declaration on Intellectual Freedom and Social Responsibility (1990) Available at:

http://portal.unesco.org/education/es/files/12575/10431559520The_Kampala_Declarati on_on_Intellectual_Freedom_and_Social_Responsibility.doc/The+Kampala+Declarati on+on+Intellectual+Freedom+and+Social+Responsibility.doc (accessed 23 February 2011). 


\section{About the authors}

Johannes Britz is currently Provost and Vice Chancellor for Academic Affairs, and Professor in the School of Information Studies, at the University of Wisconsin-Milwaukee, Milwaukee, USA. Dr. Britz holds two doctoral degrees from the University of Pretoria in South Africa and has also been appointed as Professor Extraordinary (a title used in South Africa for distinguished researchers) at the School of Information Technology at the same institution. He is co-editor of the International Review of Information Ethics (IRIE) and serves on the editorial board of a number of academic journals. He is a member of the advisory board of the International Research Foundation for Development and he is a member of national and international commit-tees in Higher Education. Dr. Britz has broad international experience both as a researcher and consultant. Dr. Britz has a very specific interest in social justice and information poverty and works primarily in Africa on these topics. Con-tact: University of Wisconsin-Milwaukee, 215 Chapman Hall, Milwaukee, WI 53211. Tel. p1-414-229-4501. Email: britz@uwm.edu

Anthony Hoffmann is a PhD candidate at the School of Information Studies, University of Wisconsin-Milwaukee. His research interests lie at the intersection of information technology and moral/political philosophy, in particular the relationship between information, tech-nological design and liberal theories of social justice. Contact: School of Information Studies, University of Wisconsin - Milwaukee, NWQ-B, 3rd Floor, PO Box 413, Milwaukee, WI 53201 USA. Tel p1-414-229-4707. Email: hoffma89@uwm.edu

Peter Lor, MBibl, DPhil, DPhil, has had a long career in librarianship, mainly in South Africa. When the National Library of South Africa was created in 1999 he became South 
Africa's first National Librarian. From 2005 to 2008 he was Secretary General of the International Feder-ation of Library Associations and Institutions (IFLA). From 2009 to 2011 he was a visiting professor in the School of Information Studies, University of Wisconsin-Milwaukee, where he still teaches an online course in international and comparative librarianship. Since 1998 he has been an extraordinary professor in the Department of Information Science, University of Pretoria. A frequent speaker at national and international conferences, he is the author of over 160 professional and research publications. His recent research focuses on international and comparative librar-ianship. Contact: Department of Information Science, Uni-versity of Pretoria, PO Box 884, Sedgefield, 6573, South Africa. Tel. p27 76649 3050. Email:peterjlor@gmail.com

Shana Ponelis, PhD, is a Lecturer in the School of Infor-mation Studies at the University of Wisconsin-Milwaukee. Her research interests include access to infor-mation, particularly access to information for decision-making and decision support as well as ethical considera-tions relating to access, including accessibility, particularly as it pertains to developing countries in general and to South Africa in particular. Contact: School of Information Studies, University of Wisconsin - Milwaukee, NWQ-B, Room 3420, PO Box 413, Milwaukee, WI 53201, USA. Tel. p1-414-229-2514. Email: ponelis@uwm.edu

Michael Zimmer, $\mathrm{PhD}$, is an assistant professor in the School of Information Studies at the University of Wisconsin-Milwaukee, and director of the Center for Infor-mation Policy Research. With a background in new media and Internet studies, the philosophy of technology, and information policy and ethics, Zimmer's research focuses on the ethical dimensions of new media and information technologies, with particular interest in privacy, 
social media, Internet research ethics, and values-in-design. Con-tact: School of

Information Studies, University of Wiscon-sin - Milwaukee, NWQ-B, Room 2531, PO

Box 413, Milwaukee, WI 53201, USA. Tel. p1-414-229-3627. Email:

zimmerm@uwm.edu 